Article

\title{
Fabrication of Suspended PMMA-Graphene Membrane for High Sensitivity LC-MEMS Pressure Sensor
}

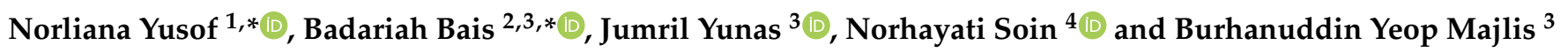 \\ 1 Faculty of Innovative Design and Technology, Universiti Sultan Zainal Abidin, \\ Kuala Terengganu 21300, Malaysia \\ 2 Department of Electrical, Electronic and Systems Engineering, Faculty of Engineering and Built Environment, \\ Universiti Kebangsaan Malaysia, Bangi 43600, Malaysia \\ 3 Institute of Microengineering and Nanoelectronics (IMEN), Universiti Kebangsaan Malaysia, \\ Bangi 43600, Malaysia; jumrilyunas@ukm.edu.my (J.Y.); burhan@ukm.edu.my (B.Y.M.) \\ 4 Department of Electrical Engineering, Faculty of Engineering, University of Malaya, \\ Kuala Lumpur 50603, Malaysia; norhayatisoin@um.edu.my \\ * Correspondence: norliana@unisza.edu.my (N.Y.); badariah@ukm.edu.my (B.B.)
}

Citation: Yusof, N.; Bais, B.; Yunas, J.; Soin, N.; Majlis, B.Y. Fabrication of Suspended PMMA-Graphene Membrane for High Sensitivity LC-MEMS Pressure Sensor. Membranes 2021, 11, 996. https://doi.org/10.3390/ membranes11120996

Academic Editor: Metin Uz

Received: 28 November 2021 Accepted: 17 December 2021 Published: 20 December 2021

Publisher's Note: MDPI stays neutral with regard to jurisdictional claims in published maps and institutional affiliations.

Copyright: (c) 2021 by the authors. Licensee MDPI, Basel, Switzerland. This article is an open access article distributed under the terms and conditions of the Creative Commons Attribution (CC BY) license (https:// creativecommons.org/licenses/by/ $4.0 /)$.

\begin{abstract}
The LC-MEMS pressure sensor is an attractive option for an implantable sensor. It senses pressure wirelessly through an LC resonator, eliminating the requirement for electrical wiring or a battery system. However, the sensitivity of LC-MEMS pressure sensors is still comparatively low, especially in biomedical applications, which require a highly-sensitive sensor to measure lowpressure variations. This study presents the microfabrication of an LC wireless MEMS pressure sensor that utilizes a PMMA-Graphene (PMMA/Gr) membrane supported on a silicon trench as the deformable structure. The (PMMA/Gr) membrane was employed to increase the sensor's sensitivity due to its very low elastic modulus making it easy to deform under extremely low pressure. The overall size of the fabricated sensor was limited to $8 \mathrm{~mm} \times 8 \mathrm{~mm}$. The experimental results showed that the capacitance value changed from $1.64 \mathrm{pF}$ to $12.32 \mathrm{pF}$ when the applied pressure varied from 0 to $5 \mathrm{psi}$. This capacitance variation caused the frequency response to change from $28.74 \mathrm{MHz}$ to $78.76 \mathrm{MHz}$. The sensor sensitivity was recorded with a value of $193.45 \mathrm{kHz} / \mathrm{mmHg}$ and a quality factor of 21. This study concludes that the (PMMA/Gr) membrane-based LC-MEMS pressure sensor has been successfully designed and fabricated and shows good potential in biomedical sensor applications.
\end{abstract}

Keywords: (PMMA/Gr) membrane; LC-MEMS pressure sensor; microfabrication

\section{Introduction}

In the past few years, various polymer materials for highly flexible capacitive membranes have been studied by many researchers [1-7] to replace typical silicon membranes. This vast interest is because most polymers have low elastic modulus, which produces a large displacement in response to pressure variation and produces higher mechanical sensitivity [8]. Extensive research has recognized the graphene role in bio-integrated soft electronics due to its excellent properties. Recently, the use of graphene as a suspended membrane for MEMS devices is gaining more traction among researchers because of its excellent mechanical characteristics as its own nature's thinnest membrane $[9,10]$, highly elastic deformation, high tensile strength [11], high conductivity and potentially high biocompatibility [10]. Moreover, graphene has a strong adhesive force to various substrates such as silicon nitride and silicon oxide [12] due to its van der Waals forces, large-scale surface and flatness [13]. These properties make the graphene membrane a promising material for the freestanding membrane, which can be applied as pressure sensors. Generally, graphene is always used with polymers such as PMMA or PDMS as a holder to allow it to remain suspended and subsequently form a freestanding graphene membrane [3-5,14,15]. 
In designing an implantable MEMS sensor, several important critical factors need to be considered to achieve the targeted specifications as a high-performance sensor. Some of the requirements that need to be considered during the design process are the appropriate sensing method, measurement range and precision, frequency response, size, material and telemetry consideration. In biomedical applications, especially for implantable sensors, passive telemetry of inductor-capacitor (LC) MEMS pressure sensors is preferable because this passive wireless sensor does not require batteries to operate, making the system more compact [16]. With the advancement in micromachining technologies, miniaturized LC pressure sensors entrenched in resonant theory became viable and received attention. In LC-based systems, the capacitive membrane, which will bear the applied pressure, plays an important role. When external pressure is applied to the membrane, the elastomeric dielectric layer displays distinctive deformity, prompting a variety in the capacitance. A graphene-based membrane was proposed for the LC-MEMS pressure sensor, considering its characteristics and potential for a capacitive pressure sensor. In the LC-MEMS pressure sensor system, a capacitive membrane needs to be attached with a planar microcoil-shaped inductor to form an LC resonator. When coupling to the external coil, this LC resonator will allow the changes of the sensor's frequency response due to changes in capacitance or inductance, which can be detected remotely.

Several design specifications must be achieved before designing an LC-MEMS sensor for implantable application, such as the sensor size, safe operating frequency range and high sensitivity to allow detection in a low-pressure variation. One of the challenges in designing implantable sensors is to make them as small as possible so that they can be inserted into the human body without harming the health of the user. In terms of the size, MEMS pressure sensor implants should be less than the organ to be placed. Critically, implant sensors have a size of less than $1 \mathrm{~cm}^{2}$ [16-22]. In their studies, Weaver et al. (2010) [23] and Kim et al. (2014) [24] managed to design sensors with diameter sizes of $10 \mathrm{~mm}$ and $8 \mathrm{~mm}$, respectively, for pressure detection applications in the bladder. Meanwhile, Li et al. (2020) developed an LC pressure sensor with the dimensions of $3 \mathrm{~mm} \times 15 \mathrm{~mm}$, specifically designed to monitor intracranial pressure (ICP) [25]. This study set the maximum sensor size at $8 \mathrm{~mm}$ based on the previous reports for biomedical implantation applications [16]. The sensor should be able to detect low-pressure changes in the range of 0 to $150 \mathrm{mmHg}$ [26] with a frequency response within the range of $10-100 \mathrm{MHz}$ for biomedical applications. Previous research revealed that the $10-100 \mathrm{MHz}$ operating frequencies are safe for in vivo wireless measurements [27]. The sensitivity of the LC-MEMS pressure sensor from previous studies was in the range between 2 to $162 \mathrm{kHz} / \mathrm{mmHg}[16-22,25,28]$. However, sensitivity values at higher rates are required for more accurate and precise measurements. In the case of implantable pressure monitoring applications, the design specifications for this MEMS pressure sensor are as shown in Table 1.

Table 1. Design specifications of the LC-MEMS pressure sensor for biomedical implantation applications.

\begin{tabular}{cc}
\hline Parameter & Value \\
\hline Pressure range & $0-75 \mathrm{mmHg}($ normal) \\
Frequency response & $\sim 150 \mathrm{mmHg}$ (abnormal) [26] \\
Size & $10-100 \mathrm{MHz}[27]$ \\
Sensor sensitivity & $8 \mathrm{~mm} \times 8 \mathrm{~mm} \mathrm{[16]}$ \\
& $2-162 \mathrm{kHz} / \mathrm{mmHg}[16-22,25,28]$ \\
\hline
\end{tabular}

This study reported the feasibility of using (PMMA/Gr) membranes to measure capacitance changes in a low-pressure sensing environment. These results suggested that the capacitance changes can be successfully adopted in an integrated planar microcoil design, with the potential development of an LC-MEMS pressure sensor for biomedical implantation applications. 


\section{LC-MEMS Pressure Sensor Working Principle}

The electrical model of the LC wireless sensing system is shown in Figure 1.

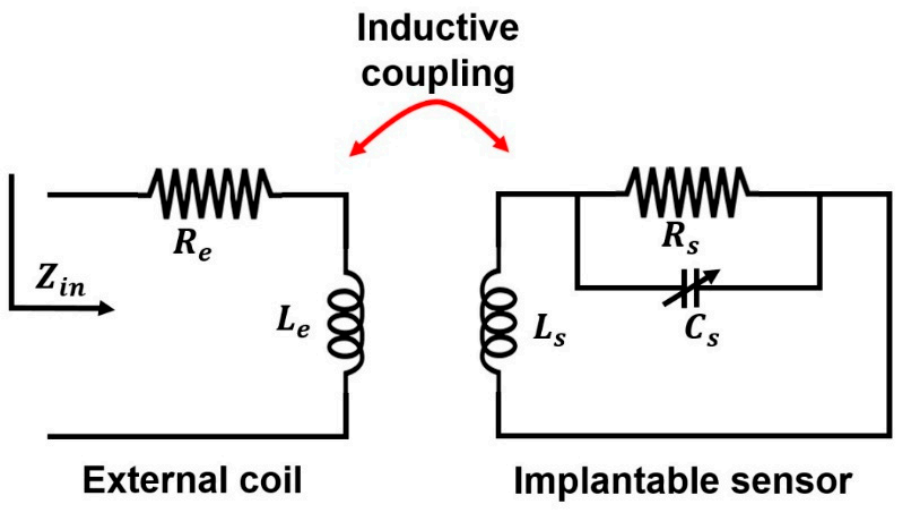

Figure 1. The electrical model of the LC wireless sensing system.

Capacitor, $C_{S}$, inductor, $L_{S}$ and series resistance, $R_{S}$, modelled the LC pressure sensor. Inductance, $L_{e}$, represents the readout coil, which is in series with resistance, $R_{e}$. Faraday's law states that the resistance of the wireless system, which is similar to the input viewed from the readout coil, can be retrieved from circuit analysis as follows

$$
\begin{aligned}
Z_{i n}(\omega)=R_{e}+ & j \omega L_{e}+\frac{(\omega M)^{2} R_{s}}{\left(R_{s}-\omega^{2} R_{s} C_{s} L_{s}\right)^{2}+\omega^{2} L_{s}^{2}} \\
& +j \frac{(\omega M)^{2}\left(\omega R_{s} C_{s}\right)\left(R_{s}-\omega^{2} R_{s} C_{s} L_{s}\right)-\omega L_{s}}{\left(R_{s}-\omega^{2} R_{S} C_{s} L_{s}\right)^{2}+\omega^{2} L_{s}{ }^{2}}
\end{aligned}
$$

where

$$
M=k\left(L_{e} L_{s}\right)^{1 / 2}
$$

demonstrates the mutual inductance between readout coil and sensor coil, whereas $k$ is the inductive coupling coefficient between both coils. The real part of input impedance, with respect to the angular frequency $\omega$, is as follows

$$
\frac{d R_{e}\left(Z_{i n}(\omega)\right)}{d \omega}=\frac{d}{d \omega}\left\{R_{e}+\frac{(\omega M)^{2} R_{s}}{\left(R_{s}-\omega^{2} R_{s} C_{s} L_{s}\right)^{2}+\omega^{2} L_{s}^{2}}\right\}=0
$$

When solving Equations (1) and (3), the equations relate to the sensor's resonant frequency $[24,25]$

$$
f=\frac{1}{2 \pi} \sqrt{\frac{1}{L C}-\frac{R^{2}}{L^{2}} \cong \frac{1}{2 \pi \sqrt{L C}}} \text { if } R \ll \sqrt{\frac{L}{C}}
$$

In order to obtain the resonance frequency of a pressure-dependent sensor, the real part of the peak impedance from the readout coil was monitored. The readout coil's wireless sensor system contains an induced peak value at the resonance frequency. Furthermore, the sensor's resonance frequency was sensitive towards pressure because the sensor comes with pressure-dependent capacitance [29].

As for the value of the quality factor, $Q$, it can be calculated using Equation (5)

$$
Q=\frac{\omega_{0} L}{R}
$$

where $\omega_{0}$ is the angular resonance frequency $\left(\omega_{0}=2 \pi f\right), L$ is the inductance value and $R$ is the coil resistance value. 


\section{Methodology}

Capacitor and inductor were connected to form LC-MEMS pressure sensor, fabricated using silicon bulk micromachining (silicon cavity), CVD graphene transfer process (fabrication of (PMMA/Gr) membrane) and sputtering process (fabrication of microcoil and electrode). The steps involved in the MEMS fabrication process of the LC-MEMS pressure sensor are shown in Figure 2.

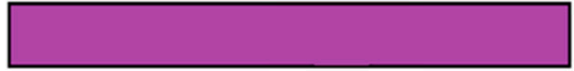

(a)

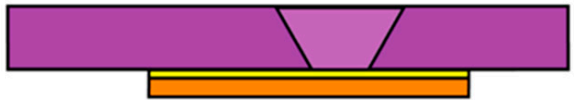

(b)

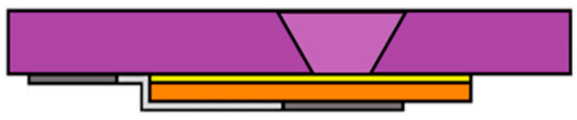

(c)

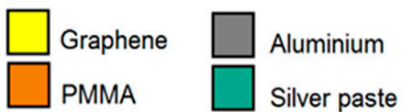

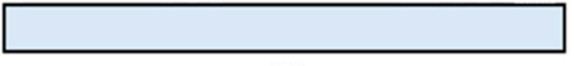

(d)

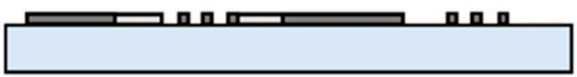

(e)

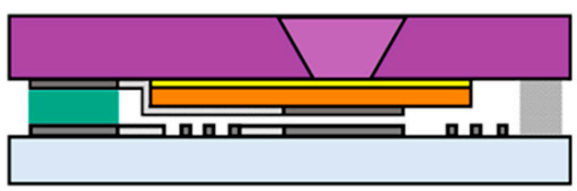

(f)

Adhesive tape

Figure 2. The fabrication process of the LC-MEMS pressure sensor: (a) silicon substrate, (b) $\mathrm{KOH}$ etch and (PMMA/Gr) membrane transfer, (c) upper plate aluminium sputter, (d) glass substrate, (e) microcoil sputter and pattern (f) silicon-glass bonding.

First, the suspended (PMMA/Gr) membrane that forms the base of the silicon trench was fabricated, hence, requiring $<100>$ oriented n-type silicon wafer of 4 -inch diameter, $525 \pm 25 \mu \mathrm{m}$ thickness, with double-sided $200 \mathrm{~nm}$ coated silicon nitride. The photolithography and buffered oxide etchant (BOE) etching process began before fabricating silicon trench using $45 \mathrm{wt} \%$ potassium hydroxide $(\mathrm{KOH})+10 \mathrm{wt} \%$ isopropyl alcohol (IPA) wet etching. The silicon nitride layer was etched to prepare the window pattern, and BOE etching was used to remove the nitride layer using $45 \mathrm{~nm} \mathrm{~min}^{-1}$ at $80^{\circ} \mathrm{C}$ etching rate. The sample of this study was immersed in a BOE solution through a double boiling process at $80{ }^{\circ} \mathrm{C}$ constant temperature. PMMA (950 PMMA A4, $950 \mathrm{~K}$ MW $4 \mathrm{wt} \%$ ) in anisole by microchemical and a monolayer thin graphene film, provided by University Wafer Inc., were used as the sensor's membrane.

By employing the wet graphene transfer process, the (PMMA/Gr) layer was then transferred onto the silicon cavity and subsequently onto the etched silicon. Creating a freestanding membrane is vital, and any mishandling during the transfer process may cause the membrane within the cavity area to rupture. Once the suspended membrane (PMMA/Gr) was successfully fabricated, the membrane was then coated with aluminium to make it an excellent electrical conductor as well as provide a current path between the membrane and the connector pad of the MEMS sensor. The direct current (DC) magnetic spark method was used to deposit a layer of aluminium atoms or molecules on the surface of the suspended membrane (PMMA/Gr).

In order to fabricate the microcoil, a Pyrex (7740) glass was used as a substrate to reduce the parallel parasitic capacitance between the microcoil's turns. After Pyrex glass was cut and cleaned in acetone and methanol, an aluminium layer was then deposited onto Pyrex glass by the DC magnetron spark process. The eight cycles of the deposition process were utilized to deposit the $4 \mu \mathrm{m}$ aluminium layer, whereby each cycle took $30 \mathrm{~min}$. The sample of the deposited aluminium was patterned with a positive mask using the lithography technique. The sample was then spin-coated with AZ1500 photoresist at 
$3000 \mathrm{rpm}$ for $30 \mathrm{~s}$ and then soft baked for $90 \mathrm{~s}$ at $90^{\circ} \mathrm{C}$ on the hot plate. The sample was then exposed to UV light for $35 \mathrm{~s}$ and soaked in the AZ300K developer for $1 \mathrm{~min}$. Next, the sample was hard-baked at $120{ }^{\circ} \mathrm{C}$ for $120 \mathrm{~s}$. In order to etch away the unwanted aluminium pattern area, the sample was dipped in a mixture of $80 \%$ phosphoric acid, $10 \%$ distilled water, $5 \%$ acetic acid and 5\% nitric acid.

The samples were soaked in the aluminium etchant for $30 \mathrm{~min}$ before dipping it into the acetone solution to remove the photoresist layer. The geometric mask of the coil were: inner size, $d i=1000 \mu \mathrm{m}$; winding number, $n=20$; trace width, $w=50 \mu \mathrm{m}$; spacing, $s=100 \mu \mathrm{m}$. Finally, the silicon and the glass were bonded together to form the $\mathrm{LC}$ resonator. The bonding layer was constructed using double-sided adhesive tape A WK6500B (Shenzhen Wenke Electronics Co., Ltd., Shenzhen, China) [30].

\section{Results and Discussion}

\subsection{Fabrication of Silicon Trench}

A wet etch property, including the etching rate and etched silicon thickness, was carefully investigated to ensure a fully etched silicon (hole). This investigation was to determine the required etching time for a fully etched silicon plane (100). Figure 3a,b show the SEM images of the top and cross-section views of the fabricated, etched silicon. The etched surfaces were observed to be smooth and free of hillocks problems. The smooth silicon surface quality was due to the IPA addition to the $\mathrm{KOH}$ solution during the wet etching [31]. From Figure 3a, the etched silicon cavity measurement has the dimension of approximately $1288 \mu \mathrm{m}^{2}$ with an original opening window of approximately $1700 \mu \mathrm{m}^{2}$ after $4 \mathrm{~h}$ of etching. This dimension is in agreement with the equation developed on the tip dimension originated from the surfaces and planes orientation, $\mathrm{W}=\mathrm{L}-(2 \mathrm{~d} / 1.414)$ with $\mathrm{W}=$ square-shaped mask, $\mathrm{L}=$ dimension of the pyramidal cavity tip and $\mathrm{d}=$ thickness of the silicon substrate [32,33]. From Figure 3b, it can be seen that the V-shaped grooves have formed between the (100) and (111) planes. This V-shaped groove was a common effect for $\mathrm{KOH}$ wet etching, where the process relied upon the crystallographic directions [34]. After $4 \mathrm{~h}$ of etching, the measured silicon thickness was $292 \mu \mathrm{m}$. This thickness indicated that the etching rate was about $1.12 \mu \mathrm{m}$ per minute. Therefore, the additional time for $\mathrm{KOH}$ etching required approximately $2.7 \mathrm{~h}$ to obtain a fully perforated silicon cavity.

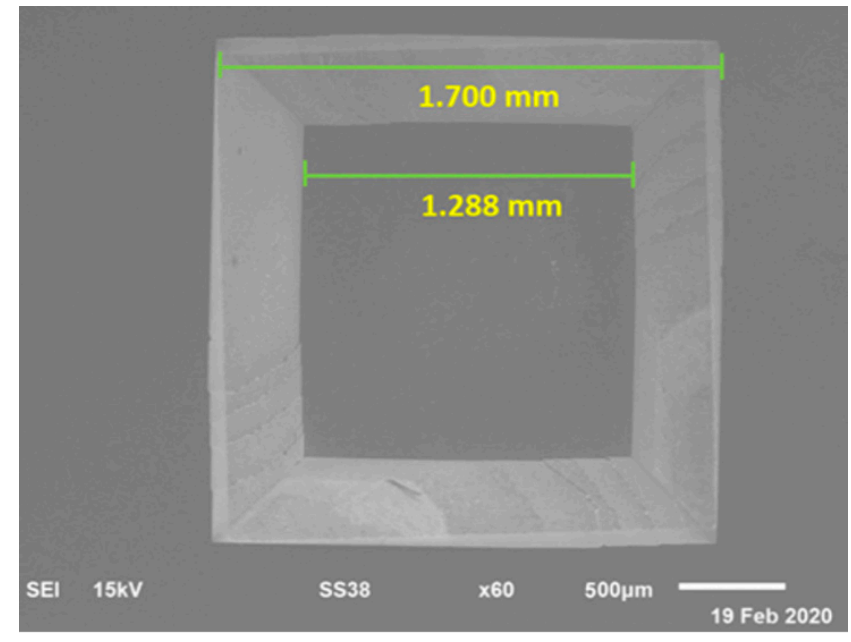

(a)

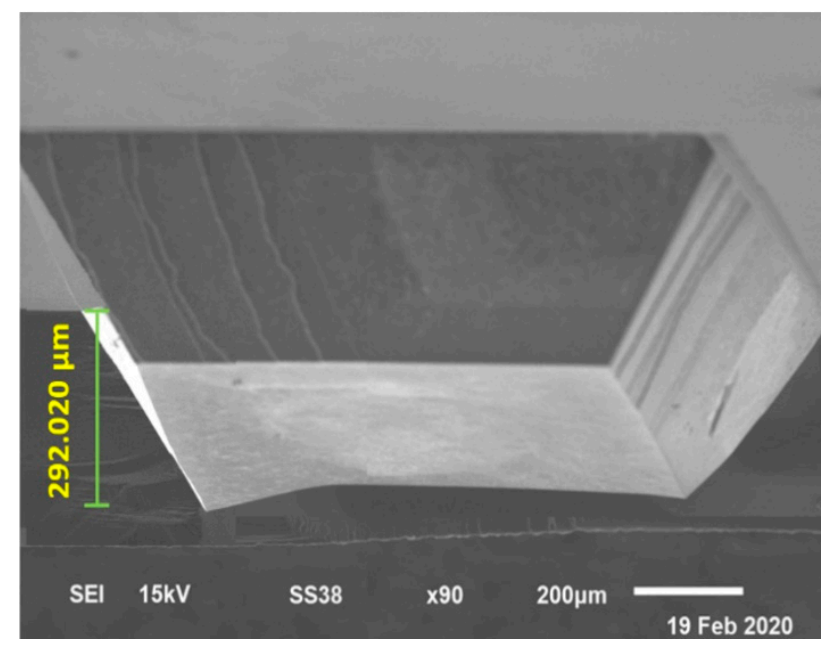

(b)

Figure 3. SEM images of: (a) Top view of etched silicon; (b) Cross-section view of etched silicon.

\subsection{Development and Characterization of Suspended PMMA/Graphene}

After the (PMMA/Gr) layer was transferred onto the silicon cavity and coated with an aluminium layer, the suspended membrane was characterized to identify the composition elements of the membrane layer. An optical microscope was used to examine the suspended 
(PMMA/Gr) membrane, as shown in Figure 4. Monolayer graphene has only $2.3 \%$ of light absorption [35], which makes it almost transparent. Observing graphene directly with an optical microscope was quite difficult. However, the top of $\mathrm{SiO}_{2} / \mathrm{Si}$ or $\mathrm{Si}_{3} \mathrm{Ni}_{4} / \mathrm{Si}$ substrate graphene was noticeably more visible because of slight interferences such as its contrast difference $[36,37]$. Under the optical microscope observation, the (PMMA/Gr) membrane contained slightly contrasting colours. The darker colour corresponds to the silicon nitride layer, and the lighter colour corresponds to the (PMMA/Gr) membrane. Figure 4 shows that the microscope images of the transferred (PMMA/Gr) were well suspended without any cracks and tears at approximately $1000 \mu \mathrm{m}^{2}$ silicon cavity area. It was also supported by the strong force of van der Waals.

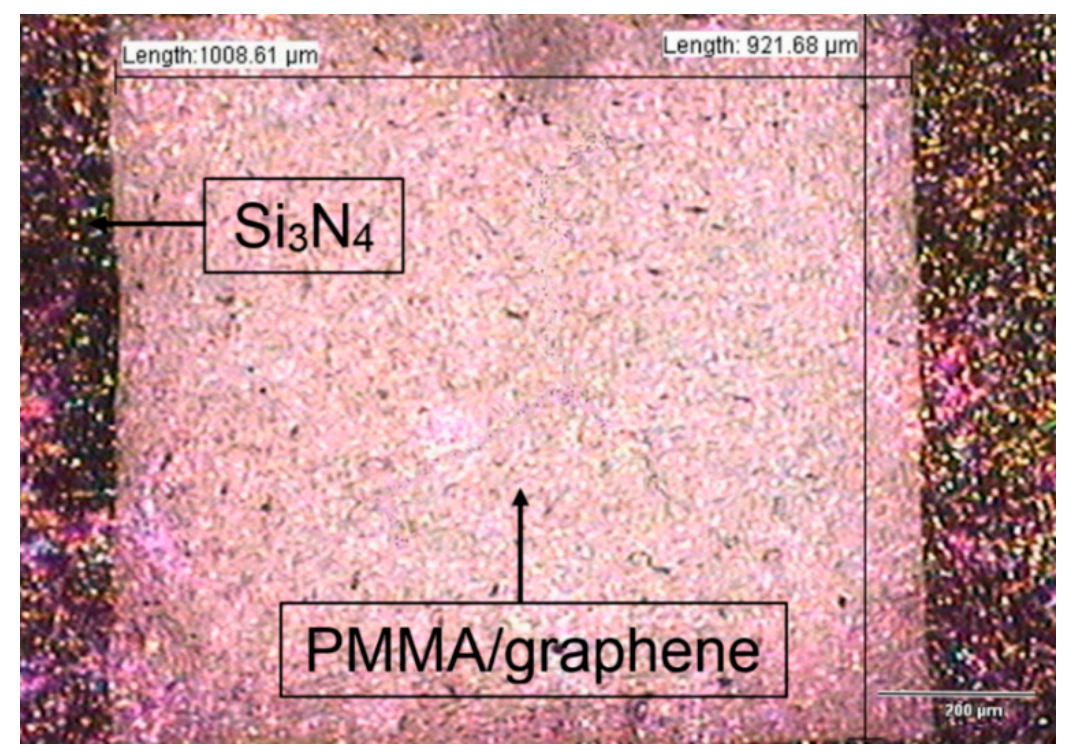

Figure 4. Optical microscopy image of suspended (PMMA/Gr) membrane system.

The existence of graphene and the number of graphene layers of the (PMMA/Gr) membrane was testified using Raman spectroscopy. The G and 2D bands are at about $1580 \mathrm{~cm}^{-1}$ and $2690 \mathrm{~cm}^{-1}$, respectively [38,39]. The number of the graphene layer was determined by the peak intensity ratio of $2 \mathrm{D}$ to peak $\mathrm{G}$ (I2D/IG) with different ratios, i.e., monolayer I2D $/$ IG $\sim 2-3$, bilayer $2>$ I2D $/$ IG $>1$ and multilayer $=$ I2D $/$ IG $<1$ [40]. The Raman spectra of freestanding (PMMA/Gr) membrane at four different locations from $1000 \mathrm{~cm}^{-1}$ to $3000 \mathrm{~cm}^{-1}$ are shown in Figure 5. Additionally, the 2D-band's graphene intensity was relatively higher than the G-band's freestanding membrane, indicating that the graphene was significant and could testify to the existence of graphene in the membrane. The inset in Figure 5 also shows the Raman peak intensity values for $G$ and 2D bands for the (PMMA/Gr) membrane. It shows that the I2D/IG ratios in all four different locations were in the range of $2-3$, hence, proving that the (PMMA/Gr) membrane has monolayer graphene. Next, the D-peak's low intensity at $1350 \mathrm{~cm}^{-1}$ (ID) concluded that this sample was made of high-quality graphene. 


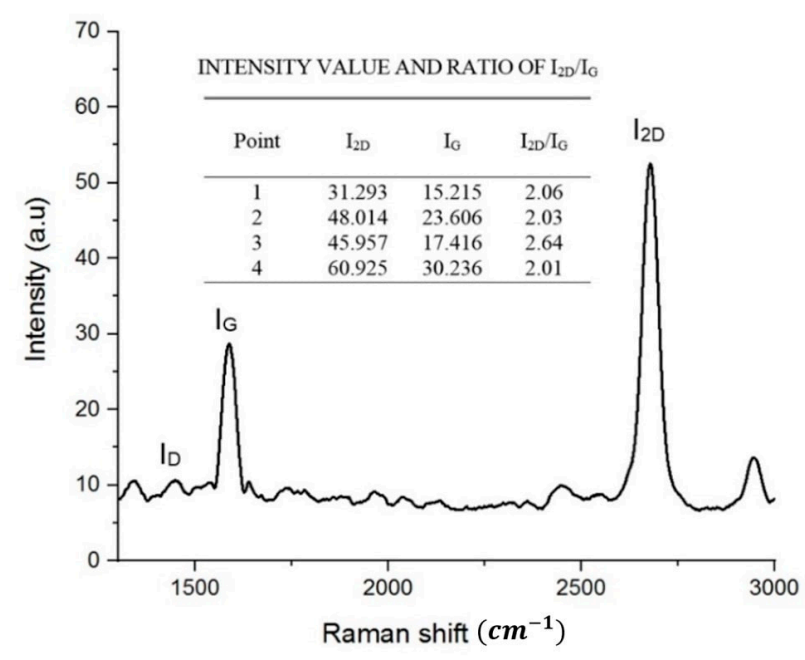

Figure 5. Raman peaks (G and 2D) for (PMMA/Gr) membrane.

\subsection{Development and Characterization of Planar Microcoil}

Figure 6 shows the SEM image of the fabricated microcoil. The microcoil was successfully fabricated without any ripple, which can cause openings or shorting of any single trace width. It is crucial to avoid any single trace width being opened or shorted as this will cause the microcoil to be dysfunctional. From Figure 6, the measured dimension of the fabricated microcoil: inner diameter size, di $\approx 1000 \mu \mathrm{m}$; trace width $\mathrm{w} \approx 50 \mu \mathrm{m}$; spacing, $\mathrm{s} \approx 100 \mu \mathrm{m}$. Additionally, from Figure 6, the thickness of the microcoil was measured to be $4.42 \mu \mathrm{m}$. As the total cycle of the sputtering time accumulated to $240 \mathrm{~min}$, the sputtering aluminium rate was deduced to be at $0.02 \mu \mathrm{m} / \mathrm{min}$. The measurements of the fabricated microcoil were performed using an Agilent 4284A precision LCR meter (Hewlett Packard, Test Equipment Depot, Melrose, MA, USA). The average values of the measured inductance and resistance values were at $2.49 \mu \mathrm{H}$ and $58.4 \Omega$ for four samples, respectively, at $1 \mathrm{MHz}$ operating frequency. These values resulted in the quality factor, $Q$, of the microcoil being at 0.27 . The $1 \mathrm{MHz}$ operating frequency was chosen due to the maximum operating frequency measured by the Agilent $4284 \mathrm{~A}$ precision LCR meter. However, the expected value of the Q-factor can be calculated using Equation (4) at higher operating frequency values.

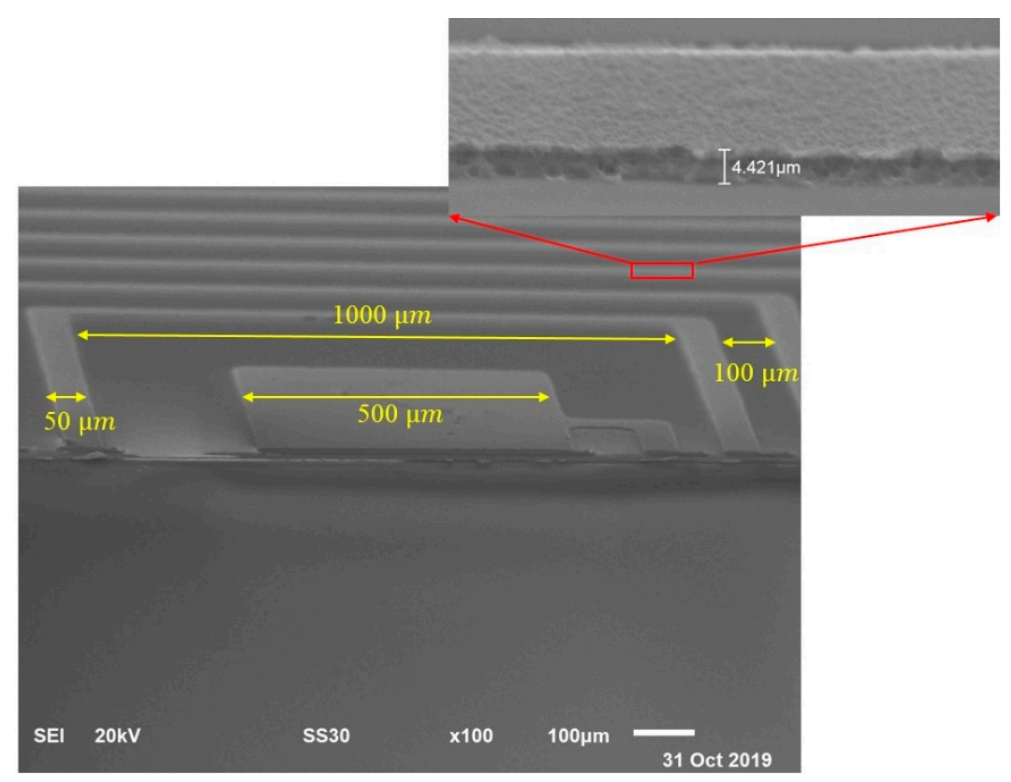

Figure 6. SEM images of fabricated microcoil. 


\subsection{Completed Structure of LC-MEMS Pressure Sensor}

The silicon substrate was then bonded onto a glass substrate, forming an LC-MEMS pressure sensor structure. Figure 7a shows the SEM image of the completed structure of the LC-MEMS pressure sensor structure without the membrane. The membrane part was excluded in Figure $7 \mathrm{a}$ to show the existence of the microcoil in the structure. The spacing between the silicon substrate and the glass substrate was adjusted to be approximately $100 \mu \mathrm{m}$ by a spacer tape and silver paste forming an air gap in the capacitive pressure sensor. The contact pad of the microcoil was bonded to the contact pad of the membrane part with the silver paste to provide an LC tank circuit. As shown in Figure 7a, the measured air gap between the bottom plate (microcoil part) and upper plate (membrane) was $96 \mu \mathrm{m}$ reaching the target of $100 \mu \mathrm{m}$ air gap. Figure $7 \mathrm{~b}$ shows the SEM image of the fabricated LC-MEMS pressure sensor structure with the suspended (PMMA/Gr) membrane. The thickness of the (PMMA/Gr) membrane was measured at approximately $0.5 \mu \mathrm{m}$. In Figure $7 \mathrm{~b}$, the membrane hid the microcoil part on the glass substrate.

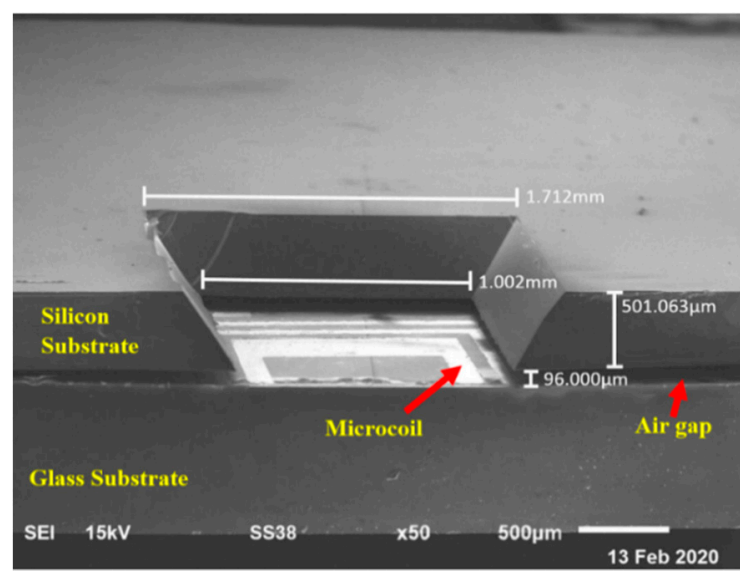

(a)

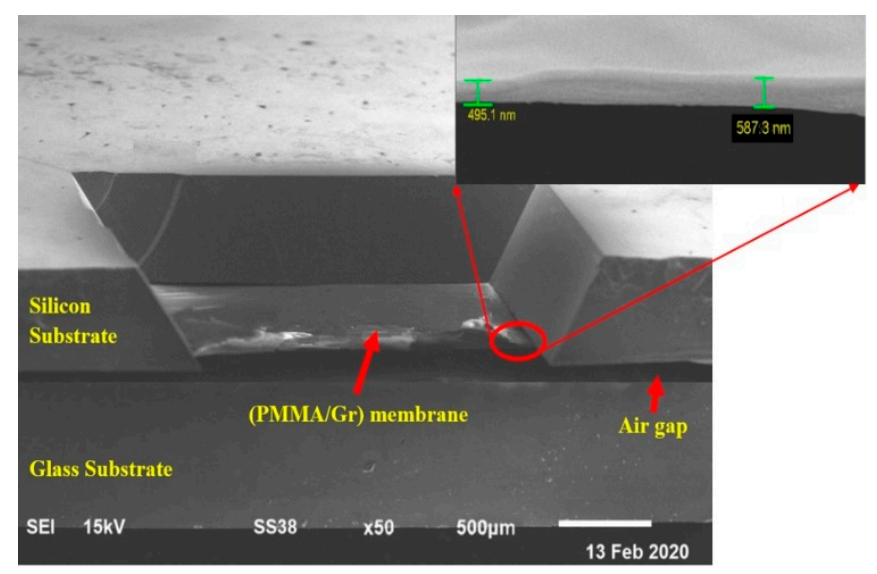

(b)

Figure 7. SEM image of LC-MEMS pressure sensor structure: (a) Top without the membrane; (b) With the suspended (PMMA/G) membrane.

\subsection{Low-Pressure Testing of LC-MEMS Pressure Sensor}

In order to examine the pressure response of the sensor, low pressure from the nitrogen gas tank was connected to the pressure chamber through a pressure regulator. The experimental setup for the measurement of the LC-MEMS pressure sensor is shown in Figure 8 . The gas pressure was controlled using a low range pressure regulator placed between the pressure gauge for the nitrogen gas tank and the pressure chamber. The sensor was placed inside the pressure chamber connected to the Agilent LCR meter to measure the capacitance values as the applied pressure was varied. Figure 9 shows the capacitance plots of four LC-MEMS pressure sensor samples tested individually against the pressure of the flowed gas. From Figure 9, the capacitance changed from $1.64 \mathrm{pF}$ to $12.32 \mathrm{pF}$ for pressure changes within 0 to 5 psi $(0 \sim 258.57 \mathrm{mmHg})$. It can also be observed that the change in the capacitance value for sample 1 was more linear than the other three samples. This nonlinearity factor might be due to the noise generated during the pressure testing. It is advisable to use a special chamber for low-pressure sensing to eliminate noise. 

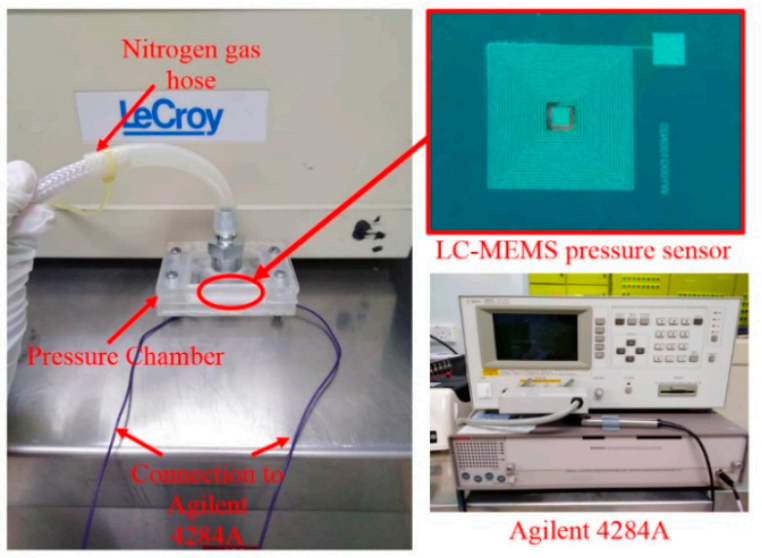

Figure 8. Testing system setup.

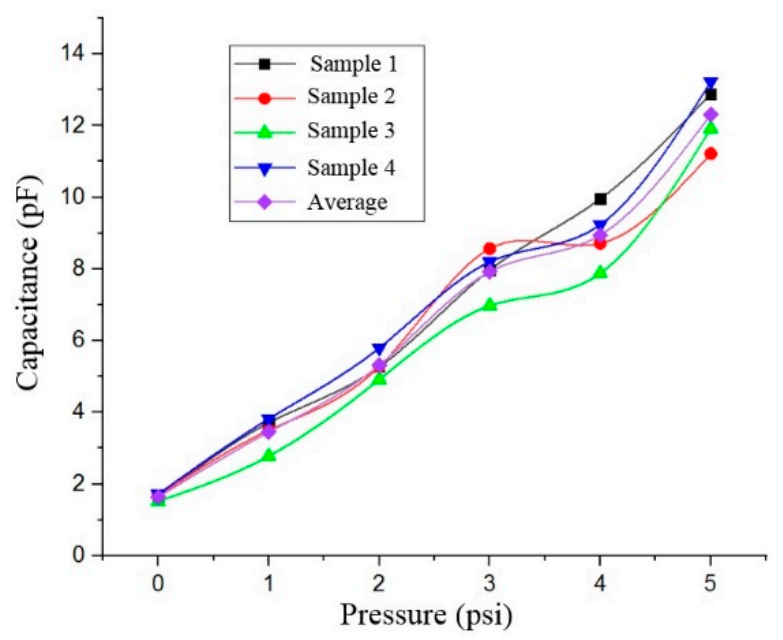

Figure 9. Capacitive responses of the developed pressure sensors.

However, it can be observed that the capacitance readings were consistent for all four samples. Referring to the microcoil characterization, the average values for the resistance and inductance of the fabricated microcoil were $58.4 \Omega$ and $2.49 \mu \mathrm{H}$, respectively. Since the measured resistance value was very small compared to the ratio of inductance and capacitance $(\mathrm{R}<<\mathrm{L} / \mathrm{C})$, the frequency response to the change in capacitance can be calculated using Equation (3). The change in frequency response to the applied pressure is shown in Figure 10. The value of this frequency change was calculated using Equation (3) by taking the average value of the capacitance from the four sensor samples measured from Figure 9. The inductance value was applied from the electrical characterization results of the microcoil. From Figure 10, the relationship between the frequency response to the varied pressure is fixed within the range of 28.74 to $78.76 \mathrm{MHz}$. While the expected value of the quality factor at the operating frequency of $78.76 \mathrm{MHz}$ is worth 21 after applying Equation (4). Based on the results obtained, it can be seen that the use of a (PMMA/Gr) material as a membrane in the LC-MEMS pressure sensor structure has successfully increased the sensor's sensitivity at a high value of $193.45 \mathrm{kHz} / \mathrm{mmHg}$, surpassing the values obtained from previous studies [16-22,28,29]. Table 2 summarizes the characteristics of the LC-MEMS pressure sensor from the simulation and fabrication results. This sensor has a high-pressure sensitivity as the (PMMA/Gr) contributed to a higher mechanical sensitivity of the sensor [8]. 


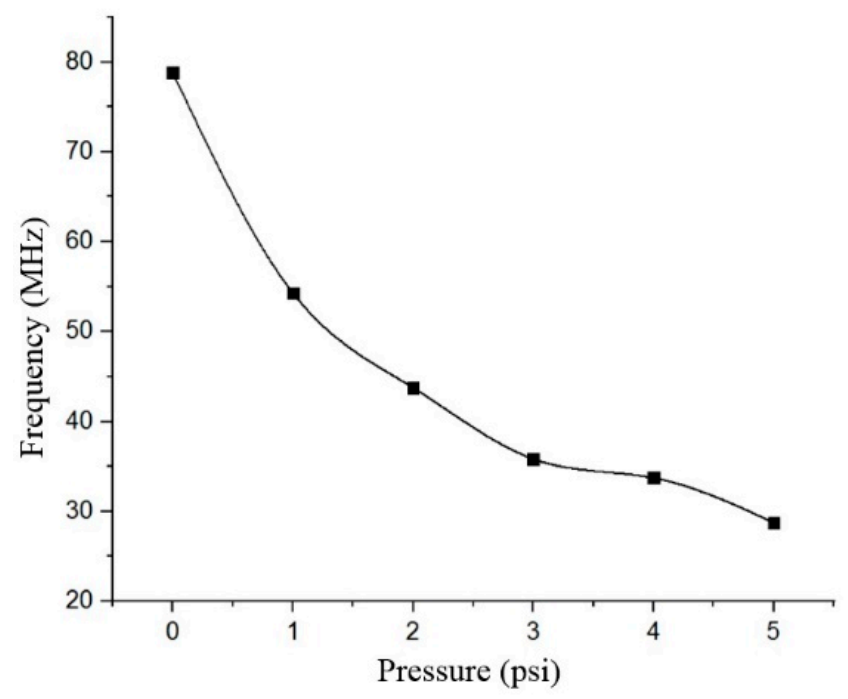

Figure 10. Frequency responses of the developed pressure sensors.

Table 2. Summarized characteristics of the fabricated LC-MEMS pressure sensor.

\begin{tabular}{cc}
\hline Parameter & Characteristics \\
\hline Membrane's material & $($ PMMA/Gr) \\
Membrane's thickness (PMMA/Gr) & $0.5 \mu \mathrm{m}$ \\
Membrane's area & $1.0 \mathrm{~mm} \times 1.0 \mathrm{~mm}$ \\
Sensor's size & $8 \mathrm{~mm}$ \\
Air gap & $96 \mu \mathrm{m}$ \\
Capacitance changes & $1.64-12.32 \mathrm{pF}$ \\
Microcoil's inductance & $2.49 \mu \mathrm{H}$ \\
Frequency changes & $28.74-78.76 \mathrm{MHz}$ \\
Quality factor & $21($ at F $=78.76 \mathrm{MHz})$ \\
Sensor's sensitivity & $193.45 \mathrm{kHz} / \mathrm{mmHg}$ \\
\hline
\end{tabular}

\section{Conclusions}

An LC-MEMS pressure sensor was developed using a MEMS fabrication process, which incorporated a microstructure of suspended (PMMA/Gr) membrane with an aluminium planar micro coil as the wireless-sensing medium. This sensor was designed for pressure monitoring purposes in biomedical implantation applications. Based on the fabrication results, the suspended (PMMA/Gr) membrane was successfully fabricated on the silicon etch cavity. The silicon cavity was realized by the bulk micromachining technique using a $45 \mathrm{wt} \% \mathrm{KOH}+10 \mathrm{wt} \%$ IPA etchant. Meanwhile, the suspended (PMMA/Gr) membrane was realized by employing a graphene wet transfer process using $\mathrm{Fe}_{3} \mathrm{Cl}_{4}$ etchant. The planar microcoil was successfully fabricated by the surface micromachining method utilizing the DC sputtering magnetron method. The fabricated LC-MEMS pressure sensor was tested in a low-pressure environment. The experimental results show that the capacitance varied from $1.64 \mathrm{pF}$ to $12.32 \mathrm{pF}$ as the pressure changed from 0 to $5 \mathrm{psi}$ ( 0 to $258.57 \mathrm{mmHg}$ ). These variations of the capacitance caused the resonance frequency to vary from 28.74-78.76 MHz. From the results and analysis, this LC-MEMS pressure sensor, which applied the PMMA/Gr as a suspended membrane, has produced a high sensitivity value of $193.45 \mathrm{kHz} / \mathrm{mmHg}$ suitable for implantable pressure sensing application. It is recommended for future works to focus on the microcoil design, taking into consideration the material selection and process, so that the Q-factor can be improved. 
Author Contributions: Conceptualization, N.Y. and B.B.; methodology, N.Y.; software, N.Y.; validation, N.Y. and B.B. formal analysis, N.Y.; investigation, N.Y. and J.Y.; resources, B.B., N.S. and B.Y.M.; data curation, N.Y. and J.Y.; writing - original draft preparation, N.Y.; writing-review and editing, B.B. and J.Y.; visualization, N.Y. and B.B.; supervision, B.B., N.S. and B.Y.M.; project administration, B.B.; funding acquisition, B.B. All authors have read and agreed to the published version of the manuscript.

Funding: This research was funded by Universiti Kebangsaan Malaysia, grant number DIP-2021-011.

Institutional Review Board Statement: Not applicable.

Data Availability Statement: Not applicable.

Acknowledgments: The authors would like to acknowledge the Centre for Research \& Instrumentation Management (CRIM), UKM for the FESEM and Raman analyses and the Institute of Microengineering and Nanoelectronics (IMEN), UKM for the cleanroom facilities.

Conflicts of Interest: The authors declare no conflict of interest. The funders had no role in the design of the study; in the collection, analyses, or interpretation of data; in the writing of the manuscript, or in the decision to publish the results.

\section{References}

1. Cui, J.; Zhang, B.; Duan, J.; Guo, H.; Tang, J. A micro-pressure sensing method based on the micropatterned electrodes filled with the microspheres. Materials 2017, 10, 1439. [CrossRef] [PubMed]

2. Mitrakos, V.; Macintyre, L.; Denison, F.C.; Hands, P.J.W.; Desmulliez, M.P.Y. Design, manufacture and testing of capacitive pressure sensors for low-pressure measurement ranges. Micromachines 2017, 8, 41. [CrossRef]

3. Dinh, T.H.N.; Martincic, E.; Dufour-Gergam, E.; Joubert, P.Y. Mechanical characterization of PDMS films for the optimization of polymer based flexible capacitive pressure microsensors. J. Sens. 2017, 2017, 8235729. [CrossRef]

4. Berger, C.; Phillips, R.; Pasternak, I.; Sobieski, J.; Strupinski, W.; Vijayaraghavan, A. Touch-mode capacitive pressure sensor with graphene-polymer heterostructure membrane. 2D Mater. 2018, 5, 015025. [CrossRef]

5. Woo, S.T.; Han, J.-H.; Lee, J.H.; Cho, S.; Seong, K.-W.; Choi, M.; Cho, J.-H. Realization of a high sensitivity microphone for a hearing aid using a graphene-PMMA laminated diaphragm. ACS Appl. Mater. Interfaces 2017, 9, 1237-1246. [CrossRef]

6. Koley, G.; Liu, J.; Nomani, M.W.; Yim, M.; Wen, X.; Hsia, T.Y. Miniaturized implantable pressure and oxygen sensors based on polydimethylsiloxane thin films. Mater. Sci. Eng. C 2009, 29, 685-690. [CrossRef] [PubMed]

7. Xue, N.; Chang, S.; Lee, J.B. A SU-8-based microfabricated implantable inductively coupled passive RF wireless intraocular pressure sensor. J. Microeletromech. Syst. 2012, 21, 1338-1346. [CrossRef]

8. Bais, B.; Yusof, N.; Soin, N.; Yunas, J.; Majlis, B.Y. Development and characterization of freestanding poly(methyl methacrylate)/monolayer graphene membrane. IEEE Access 2020, 8, 29702-29710. [CrossRef]

9. Lau, C.N.; Bao, W.; Velasco, J. Properties of suspended graphene membranes. Mater. Today 2012, 15, 238-245. [CrossRef]

10. Akiwande, D.; Brennan, C.J.; Bunch, J.S.; Egberts, P.; Felts, J.R.; Gao, H.; Huang, R.; Kim, J.S.; Li, T.; Li., Y.; et al. A review on mechanics and mechanical properties of 2D materials-Graphene and beyond. Extrem. Mech. Lett. 2017, 13, 42-77. [CrossRef]

11. Berger, C.; Phillips, R.; Centeno, A.; Zurutuza, A.; Vijayaraghavan, A. Capacitive pressure sensing with suspended graphenepolymer heterostructure membranes. Nanoscale 2017, 9, 17439-17449. [CrossRef]

12. Dash, S.; Patnaik, A. Impact of silicon-based substrates on graphene THz antenna. Phys. E Low-Dimens. Syst. Nanostruct. 2021, 126, 114479. [CrossRef]

13. Bunch, J.S.; Dunn, M.L. Adhesion mechanics of graphene membranes. Solid State Commun. 2021, 152, 1359-1364. [CrossRef]

14. Kou, H.; Zhang, L.; Tan, Q.; Liu, G.; Dong, H.; Zhang, W.; Xiong, J. Wireless wide-range pressure sensor based on graphene/PDMS sponge for tactile monitoring. Sci. Rep. 2019, 9, 3916. [CrossRef]

15. Cheng, L.; Wang, R.; Hao, X.; Liu, G. Design of flexible pressure sensor based on conical microstructure PDMS-bilayer graphene. Sensors 2021, 21, 289. [CrossRef]

16. Huang, Q.; Dong, L.; Wang, L. LC Passive wireless sensors toward a wireless sensing platform: Status, prospect, and challenges. J. Microelectromech. Syst. 2016, 25, 822-841. [CrossRef]

17. Zhai, J.; How, T.V.; Hon, B. Design and modelling of a passive wireless pressure sensor. CIRP Ann. Manuf. Technol. 2010, 59, 187-190. [CrossRef]

18. Hu, S.; Chen, H.; Jia, S.; Xiao, X.; Cao, Y.; Wang, W. A wireless passive extra-arterial implantable blood pressure monitoring sensing system for rats. Microsyst. Technol. 2021, 27, 2595-2603. [CrossRef]

19. De Santis, I.; Cacciotti, M. Wireless Implantable implantable and biodegradable sensors for postsurgery monitoring: Current status and future perspectives. Nanotechnology 2020, 31, 1-47. [CrossRef] [PubMed]

20. Chitnis, G.; Maleki, T.; Samuels, B.; Cantor, L.B.; Ziaie, B. A minimally invasive implantable wireless pressure sensor for continuous IOP monitoring. IEEE Trans. Biomed. Eng. 2013, 60, 250-256. [CrossRef] [PubMed] 
21. Lee, H.Y.; Choi, B.; Kim, S.; Kim, S.J.; Bae, W.J.; Kim, S.W. Sensitivity-enhanced LC pressure sensor for wireless bladder pressure monitoring. IEEE Sens. J. 2016, 16, 4715-4724. [CrossRef]

22. Benken, A.; Gianchandani, Y. Passive wireless pressure sensing for gastric manometry. Micromachines 2019, 10, 868. [CrossRef]

23. Weaver, J.N.; Alspaugh, J.C.; Behkam, B. Toward a minimally invasive bladder pressure monitoring system: Model bladder for in vitro testing. In Proceedings of the 3rd IEEE RAS EMBS International Conference on Biomedical Robotics and Biomechatronics, Tokyo, Japan, 26-29 September 2010; pp. 638-643.

24. Dakurah, M.N.; Koo, C.; Choi, W.; Joung, Y.H. Implantable bladder sensors: A methodological review. Int. Neurourol. J. 2015, 19, 133-141. [CrossRef]

25. Li, Y.; Zhao, M.; Wei, Q.; Yu, J.; Chen, J.; Chen, D.; Wang, J. Wireless passive intracranial pressure sensor based on vacuum packaging. IEEE Sens. J. 2020, 20, 11247-11255. [CrossRef]

26. Yu, L.; Kim, B.J.; Meng, E. Chronically implanted pressure sensors: Challenges and state of the field. Sensors 2014, 14, 20620-20644. [CrossRef]

27. Luo, M.; Martinez, A.W.; Song, C.; Herrault, F.; Allen, M.G. A microfabricated wireless RF pressure sensor made completely of biodegradable materials. J. Microelectromech. Syst. 2014, 23, 4-13. [CrossRef]

28. Farooq, M.; Iqbal, T.; Vazquez, P.; Farid, N.; Thampi, S.; Wijns, W.; Shahzad, A. Thin-film flexible wireless pressure sensor for continuous pressure monitoring in medical applications. Sensors 2020, 20, 6653. [CrossRef]

29. Peng, Y.; Wang, T.; Jiang, W.; Liu, X.; Wen, X.; Wang, G. Modeling and optimization of inductively coupled wireless bio-pressure sensor system using the design of experiments method. IEEE Trans. Compon. Packag. Manuf. Technol. 2018, 8, 65-72. [CrossRef]

30. Yang, X.; Wang, Y.; Qing, X. A flexible capacitive pressure sensor based on ionic liquid. Sensors 2018, 18, 2395. [CrossRef]

31. Burham, N.; Hamzah, A.A.; Yunas, J.; Majlis, B.Y. Electrochemically etched nanoporous silicon membrane for separation of biological molecules in mixture. J. Micromech. Microeng. 2017, 27, 075021. [CrossRef]

32. Yusof, N.; Bais, B.; Majlis, B.Y.; Soin, N.; Yunas, J. Optimization of KOH etching process for MEMS square diaphragm using response surface method. Indones. J. Electr. Eng. Comput. Sci. 2019, 15, 113. [CrossRef]

33. Abidin, U.; Majlis, B.Y.; Yunas, J. Fabrication of pyramidal cavity structure with micron-sized tip using anisotropic KOH etching of silicon (100). J. Teknol. 2015, 74, 137-148. [CrossRef]

34. Pal, P.; Sato, K. A comprehensive review on convex and concave corners in silicon bulk micromachining based on anisotropic wet chemical etching. Micro Nano Syst. Lett. 2015, 3, 6. [CrossRef]

35. Nair, R.R.; Blake, P.; Grigorenko, A.N.; Novoselov, K.S.; Booth, T.J.; Stauber, T.; Peres, N.M.R.; Geim, A.K. Fine structure constant defines visual transparency of graphene. Science 2018, 320, 1308. [CrossRef] [PubMed]

36. Ni, Z.H.; Yu, T.; Lu, Y.H.; Wang, Y.Y.; Feng, Y.P.; Shen, Z.X. Uniaxial strain on graphene: Raman spectroscopy study and band-gap opening. ACS Nano 2008, 2, 2301-2305. [CrossRef] [PubMed]

37. Smith, A.D.; Vaziri, S.; Niklausa, F.; Fischer, A.C.; Sterner, M.; Delin, A.; Östling, M.; Lemme, M.C. Pressure sensors based on suspended graphene membranes. Solid-State Electron. 2013, 88, 89-94. [CrossRef]

38. Ferrari, A.C.; Meyer, J.C.; Scardaci, V.; Casiraghi, C.; Lazzeri, M.; Mauri, F.; Geim, A.K. Raman spectrum of graphene and graphene layers. Phys. Rev. Lett. 2006, 97, 187401. [CrossRef] [PubMed]

39. Tang, B.; Guoxin, H.; Gao, H. Raman spectroscopic characterization of graphene. Appl. Spectrosc. Rev. 2010, 45, 369-4070. [CrossRef]

40. Nguyen, V.T.; Le, H.D.; Nguyen, V.C.; Ngo, T.T.T.; Le, D.Q.; Nguyen, X.N.; Phan, N.M. Synthesis of multi-layer graphene films on copper tape by atmospheric pressure chemical vapor deposition method. Adv. Nat. Sci. Nanosci. Nanotechnol. 2013, 4, 035012. [CrossRef] 